\title{
Weather - Temperature Pattern Prediction and Anomaly Identification using Artificial Neural Network
}

\author{
Himani Tyagi \\ Krishna Engineering College \\ Ghaziabad, Uttar Pradesh
}

\author{
Shweta Suran \\ Krishna Engineering College \\ Ghaziabad, Uttar Pradesh
}

\author{
Vishwajeet Pattanaik \\ Krishna Engineering College \\ Ghaziabad, Uttar Pradesh
}

\begin{abstract}
Temperature prediction is one of the most important and challenging task in today's world. Temperature prediction is the attempt by meteorologists to forecast the state of the atmospheric parameters such as: Temperature, Humidity, etc. The paper presents research on weather forecasting by using historical dataset. Because atmosphere pattern is complex, nonlinear system, traditional methods aren't effective and efficient. Artificial Neural Network is an influential method for resolving such problems. The proposed ANN evaluates the performance of the developed models by applying different neurons, hidden layers and transfer functions to predict temperature for 365 days of the year. The criteria used for appropriate model selection is mean square error (MSE). Contrary to similar researches the data model and workflow suggested in the paper generated lesser MSE (i.e. more accurate results) that too with reduced computational complexity (i.e. better performance).
\end{abstract}

\section{General Terms}

Algorithm, Forecast, Prediction, Pattern Recognition

\section{Keywords}

Analogue Method, Atmospheric Model, Artificial Neural Network, Data Modelling, Numerical Weather Forecasting, Interpolation, Primitive Equations, Spline, Statistical Probability, Steady-State/Trend Method.

\section{INTRODUCTION}

Weather forecasting is the most important practical reason which makes us believe that meteorology is actually a science [7]. Being perceptive weather conditions in advanced is imperative for both individuals as well as organizations [3]. Accurate weather forecasts can tell an airport control tower what information needs to be sent to airplanes that are taking off or landing, it can tell a farmer the best time for cultivate various crops, and also predict natural calamities [10].

Humans have been looking to find out ways to forecast accurate weather conditions for centuries. The Greek philosopher Theophrastus while working on nature wrote a Book of Signs, in about 300 BCE cataloguing more than 200 ways of predicting rain, wind, fair conditions, and other similar kinds of weather condition [4]. Scientifically-based weather forecasting was not imaginable until meteorologists were able to gather data related to current weather conditions from a relatively prevalent system of observing stations and presenting that data in a timely fashion. A somewhat more reliable method to weather forecasting is the Steady-State or Trend Method. The Steady-State method rely on the knowledge that weather conditions are deeply impacted by the movement of air currents that often can be enumerated quite accurately. One more similar approach to forecasting is the Analogue Method; it is called so because it uses similarities between existing maps and analogous maps of weather from the past. For instance, assume if weather map for December 10, 2002, is found to be nearly identical with a weather map for January 8, 1993. Since the weather conditions for the earlier date is already known it can be assumed that similar weather patterns would be encountered on the later date.

One more approach for weather forecasting is Atmospheric Model. It is a computer based program that produces meteorological information at given locations and altitudes. All modern models contain set of equations, used to predict the future state of the atmospheric parameters; such equations are often referred to as Primitive Equations. These equations in combination with the ideal gas law are used to develop the potential temperature, pressure, density and wind velocity in the atmosphere. Some primitive equations and high resolution models also take into consideration transport equations for pollutants and aerosols, etc. Another form of weather forecasting model makes use of a technique known Statistical Possibility. In specific locations on Earth's surface, one can safely predict the weather because consistent patterns have already been established; this is known as Statistical Possibility. Another approach for weather forecasting is the Numerical Weather Forecasting; this kind of forecasting methods make use of numerical data like: temperature, atmospheric pressure, and humidity [14]. More precisely, numerical weather prediction is related to forecasts that are obtained by applying complex mathematical calculations carried out with high-performance computational devices [9].

Recent weather conditions are also predicted using mathematical models of atmospherics/oceanic data often referred to as Numerical Weather Prediction [3, 4].Though first attempt to do the same were made in the 1920s, it wasn't till 1950s i.e. the initiation of computer simulations that numerical weather predictions produced genuine outcomes. Many international and regional forecast models are utilized in different countries worldwide, each using weather satellites, RADAR systems and other observation systems for monitoring weather in real-time.

Mathematical models are systems containing equations that attempt to describe the characteristics of the atmospheric changes that may take place within it [13]. These equations can be transcribed because the gases that comprise the atmosphere follow the same laws physics and chemistry that gases on Earth's surface follow. For instance, Charle's Law states that when a gas is heated, it tends to expand. This law applies alike to the gases in the atmosphere as it does to gases in a laboratory setup.

Keeping the above mentioned Weather Prediction Techniques in mind, it is important to understand that 
Weather forecasting is supposed to forecast the state of one, two or more days in advance [11]. It expresses itself through its impacts on soil, plant and animal growth. A huge percentage of the total annual crop loss is due to aberrant weather. Crop and animal disease are also influenced by weather. Weather anomalies directly/indirectly account for about $3 / 4^{\text {th }}$ of all annual losses in farm production. Weather forecasts for farming and agriculture can be grouped into three primary categories: short range forecast (up to 48 hours), medium range forecast (3-10 days) and long range forecast (one week to entire season); each of which play a significant role in farm operations and planning of agricultural activities. Since ancient time, significant efforts have been made towards effective rain making and weather forecasting techniques. However, timely and accurate weather forecasts could significantly reduce the damage to crops with the use of effective adjustments [10]. Such weather forecasts could support and provide guidelines for long range seasonal planning and selection of crops which are best suited according to varying climatic conditions. The bottom line being that accurate weather forecasting is imperative for effective sustainability of agricultural and industrial sector. Weather is certainly one of the most crucial factors determining the success or failure of agricultural enterprises.

The traditional methods for weather forecasting are based on parameterization, atmospheric dynamics and expertise which focuses on present data [16], but the historical database is not used. The complexity of atmospheric conditions can be realized by the fact that none of the above mentioned forecasting methods are dependable for more than a few days. This actuality does not prevent meteorologists from trying to make long-term forecasts. These forecasts might be able to predict the weather a few weeks, few months, or a year in advance. Modern weather forecasting method involves a combination of computer models, observation and knowledge of trends and patterns and ANN drawing significant attention of research workers, as it can solve the complex non-linearity problems better than the conventional existing statistical techniques.

Artificial neural networks (ANN) are parallel computational models, comprising closely interconnected adaptive processing units. One of the important characteristic of neural networks is their adaptive nature, where 'learning by example replaces programming' $[12,15]$. This feature makes the ANN techniques very attractive in application domains for solving highly nonlinear problems. During last four decades various complex problems like weather prediction, stock market prediction etc. has been evidenced to be areas with abundant scope of application of this sophisticated mathematical tool. A multilayer neural network (MLNN) can approximate any smooth, measurable function between input and output vectors by selecting an appropriate set of connecting weights and transfer functions.

The paper presents a novel method to effectively predict daily Temperature Patterns using ANNs. The proposed methodology also revealed anomalies in test data caused due to different effects of pollution and changing weather patterns.

\section{DATA MODELLING}

Data modelling is often the first step in weather prediction as the researchers first create a conceptual model of how data items relate to each other. Modelling data involves evolution of data from conceptual models to logical models ultimately to physical schemas.

Weather Prediction Models mentioned earlier model data in various forms like: Short term modelling, long term modelling, etc. For the proposed methodology various data models were analyzed and tested before coming up with the final data model.

The data model in the proposed system uses day wise data (maximum 366 days) over the duration of 4 years and 19 years for predicting the Temperatures (day wise) of the $5^{\text {th }}$ year and $20^{\text {th }}$ year, respectively.

\section{SPLINE INTERPOLATION}

Spline Interpolation can be explained as a kind of interpolation technique in which the interpolant is a special kind of piecewise-polynomial often referred to as a spline. Small interpolation errors are bound to occur when using low degree polynomials for the spline; this is why Spline Interpolation is often preferred over Polynomial Interpolation Techniques. Spline interpolation also helps avoid problems of Runge's phenomenon (in which fluctuation can occur between points when interpolating using high degree polynomials). Missing data is an enormous problem in Weather Prediction [16]. Hence weather data retrieval systems use similar techniques to handle missing data before applying the prediction models.

In the proposed method Spline Interpolation method is used for dealing with missing data. Various other techniques were tested for the same, but Spline Interpolation proved to be the most reliable method of all.

\section{ARTIFICIAL NEURAL NETWORK}

A neural network is a strong data modelling tool that is able to represent complex relationship between input and output. The inspiration for the development of neural network technology stemmed from the desire to implement an artificial system that could perform intelligent task similar to those performed by the human brain [15]. Neural network works like the human brain in the following ways: neural network obtains knowledge through learning; and neural network's information is stored within interneuron connection strengths which are known as synaptic weights.

Neural network has the capability to characterize both linear and non-linear relationship directly from the data being modelled [9]. From a given set of data, neural network model is a structure that can be tweaked or altered to create a mapping or relationship among the data set [6]. The network model is adjusted and then trained using a collection of data set which is generally referred as the training set. After successful training of the neural network it will be able to perform prediction, classification, estimation or simulation tasks on new data from the same or similar data sources.

An artificial neural network (ANN) is an information processing system that is inspired by the biological nervous system, which process information [12, 15]. The key element of this system is the new structure of the information processing system. It is composed of a huge number of highly interconnected processing elements (neurons) working in union to solve specific-complex problems [1]. Single layer perceptron network consists of a 
single layer of output nodes, in these networks the inputs are fed directly into the outputs via a sequence of weights/bias [8]. This indeed can be considered the simplest form of feed forward neural network. Inputs units are connected in a feed forward fashion with the input units fully connected to units in the hidden layer and hidden units fully connected to units in the output layer.

The model show different performance with different input styles [5]. For input there are a number of national and international weather forecasting sources are available which provide data for past many years with parameters like max temp, min temp, wind speed, precipitation, wind direction but working on all the parameters and making predictions is difficult because of the availability of super computers. So in this research study single parameter is used for making predictions. It involves the use of ANN which is the strongest tool for predictions [2]. Unlike other techniques which focus on and test ANNs based on 10:1 Input-Output Ratio [17], the proposed methodology two different ANNs were designed and compared using same datasets sculpted into two different forms (4:1 and 19:1). The data of a single city stretched from $~ 1500$ elements to $\sim 7000$, respectively. The input data was broken down into three segments $80 \%$ for training ANN, $10 \%$ for testing and $10 \%$ for validation. Combining data from various cities could theoretically predict Weather Patterns over larger areas. Contrary to belief testing proved that combining such data increases ANNs Mean Square Error (MSE) drastically; evidencing that Weather Patterns of various

Cities are less dependent on each other. Also the system mathematically ascertains that cities with higher pollution levels tend to have more number of Minor Weather Anomalies, and/or Weather Pattern Shifts.

\section{EXPERIMENTAL RESULTS}

The proposed system was tested on the Temperature Data of 326 Cities (from $1^{\text {st }}$ January 1994 to $31^{\text {st }}$ December 2014). As discussed earlier two different Neural Networks were designed for the same; first, with 4:1 Input-Output Data Ratio and second, with 19:1 Input-Output Data Ratio.

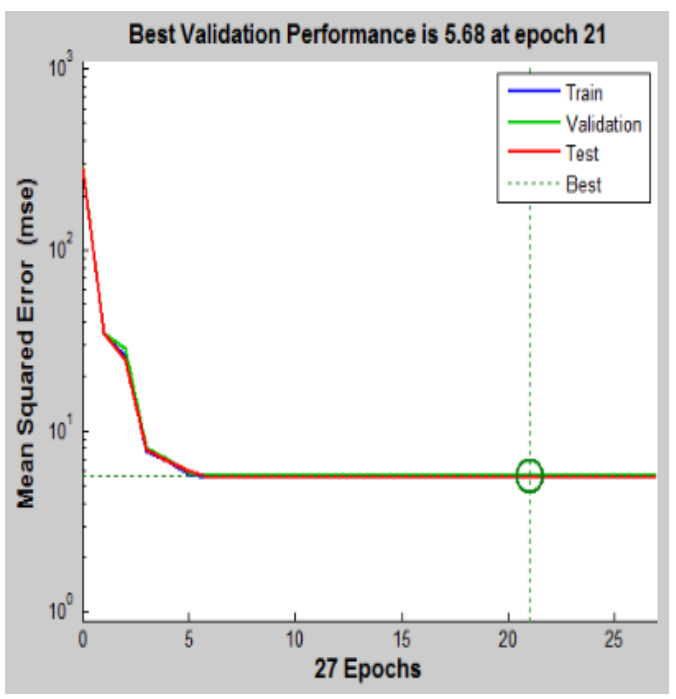

Fig 1. Evaluation of Training, Validation \& Testing Performances for 4:1 Input-Output Data Ratio [DELHI] over last 20 years

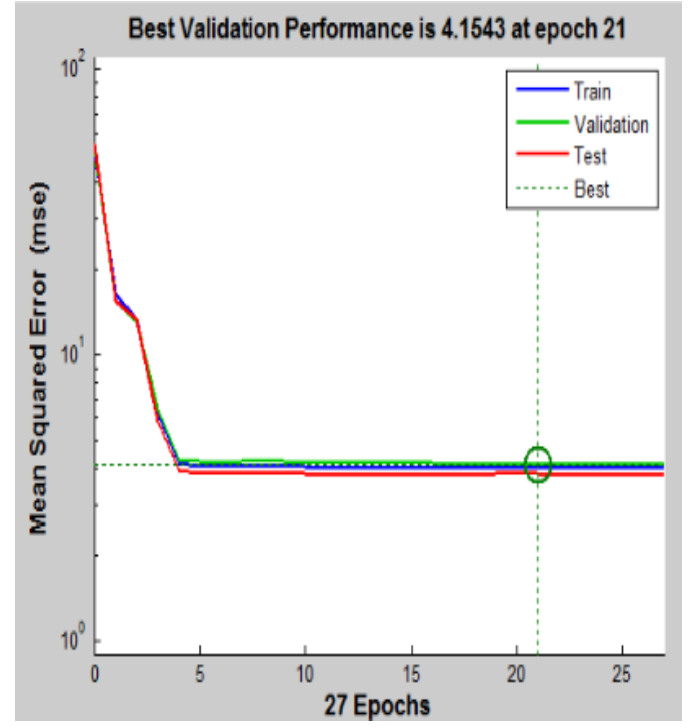

Fig 2. Evaluation of Training, Validation \& Testing Performances for 19:1 Input-Output Data Ratio [DELHI] over last 20 years

Each city's individual data adds up to 7320 data elements. Figures 1 and 2 compare the Mean Square Error evaluations of Training, Validation \& Testing Performances for the 4:1 (Input-Output Data Ratio) Neural Network; vs. 19:1 (InputOutput Data Ratio) Neural Network for Delhi over last 20 years. Figures 3 and 4 compare the Regression Plot for the 4:1 (Input-Output Data Ratio) Neural Network; vs. 19:1 (Input-Output Data Ratio) Neural Network for Delhi over last 20 years. As it can be observed in the figures the fit of the 19:1 ANN is better compared to that of the 4:1 ANN.

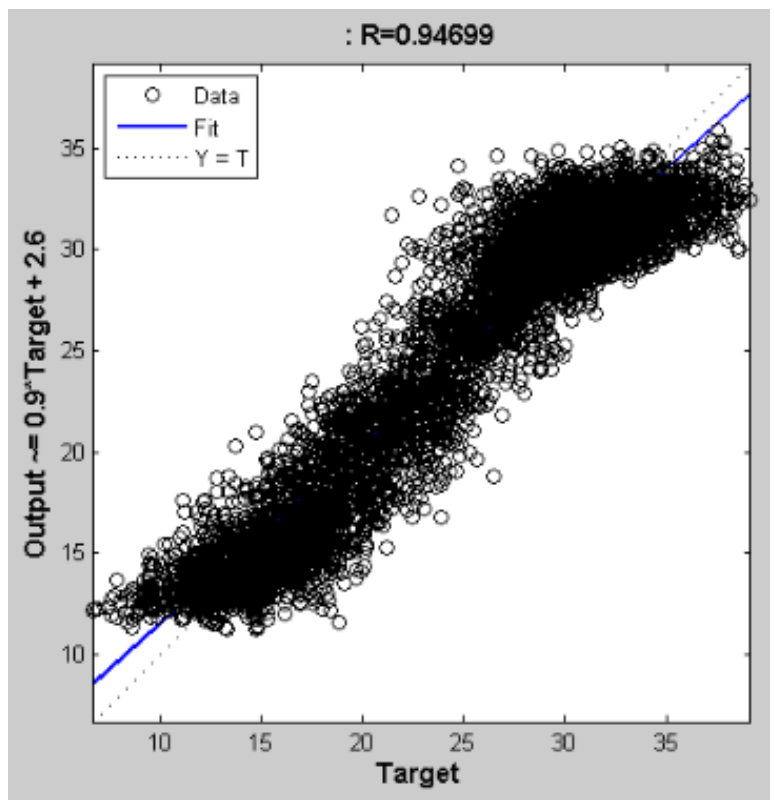

Fig 3. Regression Plot for 4:1 Input-Output Data Ratio [DELHI] over last 20 years 


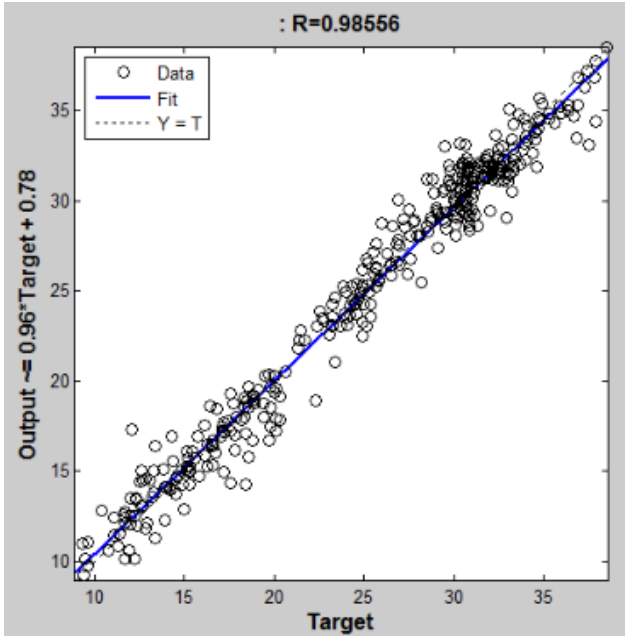

Fig 4. Regression Plot for 19:1 Input-Output Data Ratio [DELHI] over last 20 years

The Mean Square Error evaluations of Training, Validation \& Testing Performances for the 4:1 (Input-Output Data Ratio) Neural Network; vs. 19:1 (Input-Output Data Ratio) Neural Network for Delhi \& Mumbai over last 20 years is compared in figures 5 and 6 . Comparing the $4: 1$ ANN vs. 19:1 ANN, it can be clearly stated that the 19:1 ANN is able to predict temperatures more accurately. Also it can be seen that predictions based on individual city data aren't as accurate as multi-city data.

The 19:1 ANN test cases returned different MSEs for nearly all test cities. This indeed verified that the cities with factors such as higher pollution, etc. had higher tendency of temperature anomalies.

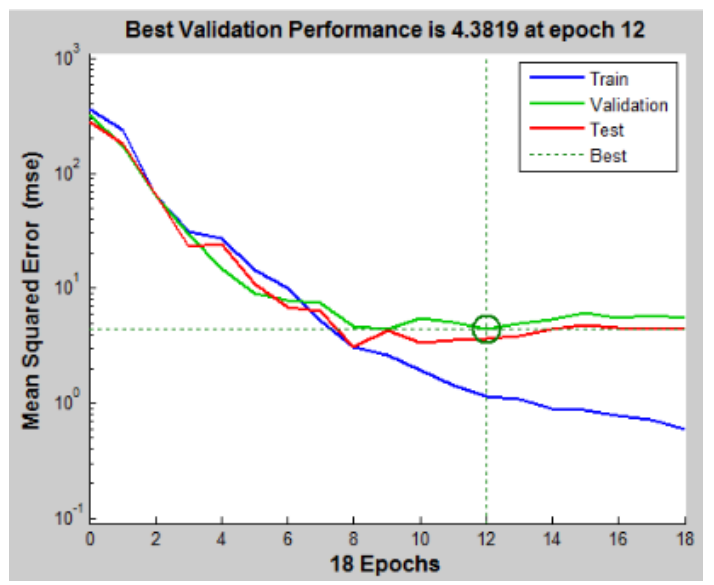

Fig 5. Evaluation of Training, Validation \& Testing Performances for 4:1 Input-Output Data Ratio [DELHI \& MUMBAI] over last 20 years

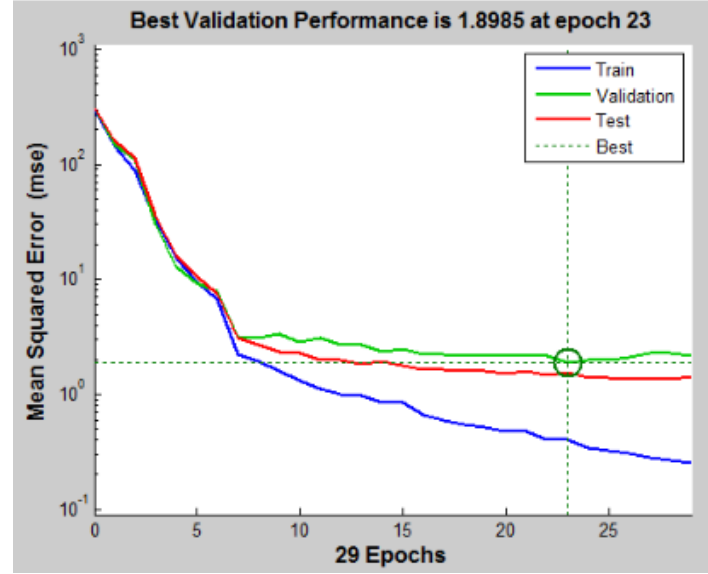

Fig 6. Evaluation of Training, Validation \& Testing Performance for 19:1 Input-Output Data Ratio [DELH] \& MUMBAI] over last 20 years

The Error Histogram for the 4:1 (Input-Output Data Ratio) Neural Network; vs. 19:1 (Input-Output Data Ratio) Neural Network for Delhi \& Mumbai over last 20 years is compared in figures 7 and 8 .

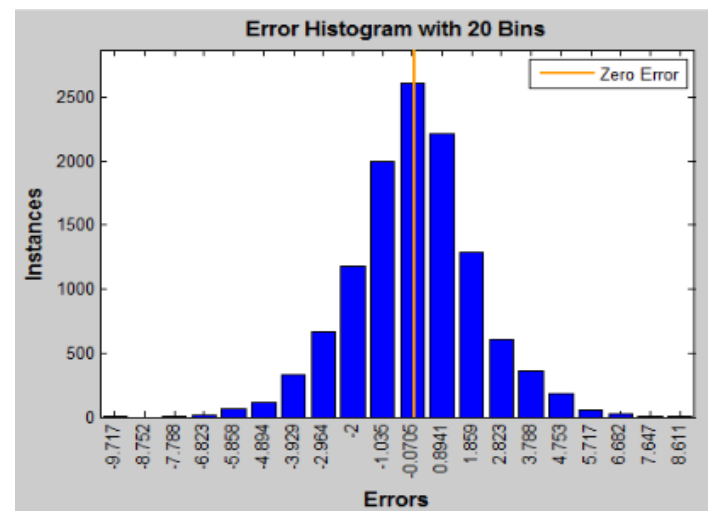

Fig 7. Error Histogram for 4:1 Input-Output Data Ratio [DELHI \& MUMBAI] over last 20 years

Comparing the two it can be noticed that; the 4:1 ANN achieves minimum MSE of around -0.0705 degree Celsius for 2500 test cases, 0.8941 degree Celsius for 2250 test cases and -1.035 degree Celsius for 2000 test cases out of 13908 test cases. Using the same it can be induced that approximately $48.53 \%$ test cases have MSE +/- 0.95 degree Celsius.

Whereas, the 19:1 ANN achieves minimum MSE of around -0.2487 degree Celsius for 190 test cases, 0.144 degree Celsius for 180 test cases and -0.5368 degree Celsius for 110 test cases out of 720 test cases. Using the same it can be induced that approximately $66.66 \%$ test cases have MSE +0.21 degree Celsius.

Proving that contrary to popular belief, the 19:1 Artificial Neural Network based on Long Term Temperature Analysis is way more effective compared to other prevalent techniques. 


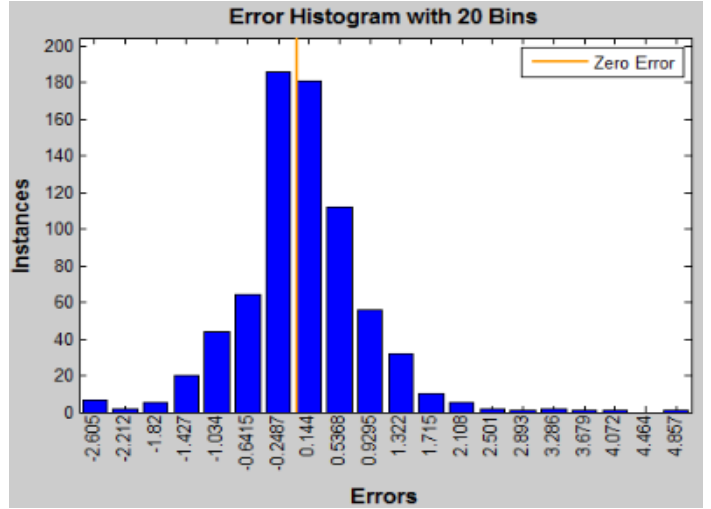

Fig 8. Error Histogram for 19:1 Input-Output Data Ratio [DELHI \& MUMBAI] over last 20 years

As discussed earlier the following conclusions can be made from the combination proposed ANN and data model:

- Day wise Long Term Prediction based on 19 years of data is more effective than prediction based on 10 years data or less.

- Variance in MSEs of cities (even within the same country i.e. less than $3000 \mathrm{KMs}$ away) proves that different cities are having varying increments/decrements in daily temperatures.

- The above mentioned variance also indicates that various cities are being affected by Global Warming differently.

"Scientific evidence for warming of the climate system is unequivocal." as stated by Intergovernmental Panel on Climate Change Global warming. Unfortunately the evidences for hasty climate variation includes: sea level rise, global temperature rise, warming oceans, shrinking ice sheets, declining artic sea ice, glacial retreat, extreme weather anomalies, ocean acidification and decreased snow cover; all of which are identified by studying historical weather data.

The model proposed in the paper is a novel attempt to identify the actuality of Global Warming using nonconventional computing techniques.

\section{COMPARISON WITH SIMILAR WORKS:}

Unlike previous methodologies the proposed paper suggests the use of following parameters for the proposed ANN (as shown in figure 9):

- Number of Neurons -4 nos.

- $\quad$ Training Function - Levenberg-Marquardt

- Transfer Function - tansigmoid

- Number of Hidden Layers - 1 nos.

Figures 10, 11 and 12 analyze the effect of number of neurons (20, 50 and 80) and the transfer function (tansigmoid or pure-linear) on the MSE in case of varying number of hidden layer (1, 5 and 10) [17].

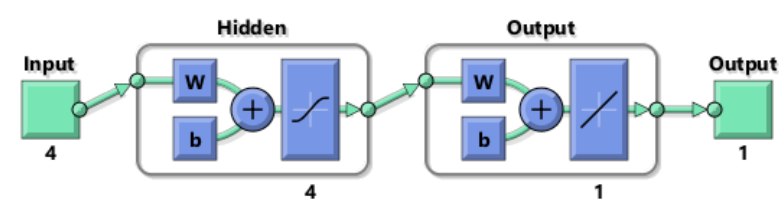

Fig 9. Proposed Neural Network Model

Compared to performances shown in Figures 10, 11 and 12 it can be clearly stated that the proposed system has lesser MSE. Also the computational complexity of the proposed method is drastically less as it utilizes lesser number of Hidden Layers and Nodes.

The proposed system has been designed in a generalized fashion keeping in mind that conventional weather prediction techniques exploit the following parameters [18]:

- Air/Soil Temperature

- Relative Humidity

- Barometric Pressure

- Wind Speed

- Solar Flux Density

- Total Solar Flux

- Dew Point/ Wet Bulb Temperature

- Heat Index

- Wind Run/Gust

- Rainfall

- Rainfall Intensity

- Hourly/Daily Evapotranspiration

The proposed ANN model is expected to work effectively with the above mentioned parameters too.

Table 1. Performance Comparison for Single Layer based ANN with Weather data for last 10 years [17]

\begin{tabular}{|c|c|c|c|c|}
\hline Samples & $\begin{array}{c}\text { Neuron } \\
\text { layer }\end{array}$ & $\begin{array}{c}\text { Transfer } \\
\text { function of } \\
\text { HL }\end{array}$ & MSE & $\begin{array}{c}\text { Stopping } \\
\text { criteria }\end{array}$ \\
\hline 365 & 20 & TANSIG & 15.4 & $\begin{array}{l}\text { Validation } \\
\text { stop }\end{array}$ \\
\hline 730 & 20 & TANSIG & 10.6 & $\begin{array}{l}\text { validation } \\
\text { stop }\end{array}$ \\
\hline 1460 & 20 & TANSIG & 2.79 & $\begin{array}{l}\text { Validation } \\
\text { stop }\end{array}$ \\
\hline 365 & 20 & PURELIN & 19.3 & Min gradient \\
\hline 730 & 20 & PURELIN & 18.8 & Min gradient \\
\hline 1460 & 20 & PURELIN & 16.1 & $\begin{array}{c}\text { Max MU } \\
\text { reached }\end{array}$ \\
\hline 365 & 50 & TANSIG & 10,3 & $\begin{array}{l}\text { Validation } \\
\text { stop }\end{array}$ \\
\hline 730 & 50 & TANSIG & 3.65 & $\begin{array}{l}\text { Validation } \\
\text { stop }\end{array}$ \\
\hline 1460 & 50 & TANSIG & 0.885 & $\begin{array}{l}\text { Validation } \\
\text { stop }\end{array}$ \\
\hline 365 & 50 & PURELIN & 18 & $\begin{array}{l}\text { Max MU } \\
\text { reached }\end{array}$ \\
\hline 730 & 50 & PURELIN & 17.6 & $\begin{array}{l}\text { Max MU } \\
\text { reached }\end{array}$ \\
\hline 1460 & 50 & PURELIN & 17.4 & $\begin{array}{l}\text { Max MU } \\
\text { reached }\end{array}$ \\
\hline 365 & 80 & TANSIG & 7.14 & $\begin{array}{l}\text { Validation } \\
\text { stop }\end{array}$ \\
\hline 730 & 80 & TANSIG & 2.71 & $\begin{array}{l}\text { Validation } \\
\text { stop }\end{array}$ \\
\hline
\end{tabular}




\begin{tabular}{|c|c|c|c|c|}
\hline 1460 & 80 & TANSIG & 0.211 & $\begin{array}{c}\text { Validation } \\
\text { stop }\end{array}$ \\
\hline 365 & 80 & PURELIN & 16.5 & Min gradient \\
\hline 730 & 80 & PURELIN & 17 & Min gradient \\
\hline 1460 & 80 & PURELIN & 18.2 & Min gradient \\
\hline
\end{tabular}

Table 2. Performance Comparison for Five Layer based ANN with Weather data for last 10 years [17]

\begin{tabular}{|c|c|c|c|c|}
\hline Samples & $\begin{array}{l}\text { Neuro } \\
\text { n layer }\end{array}$ & $\begin{array}{l}\text { Transfer } \\
\text { function of } \\
\text { HL }\end{array}$ & MSE & $\begin{array}{c}\text { Stopping } \\
\text { criteria }\end{array}$ \\
\hline 365 & 2 & TANSIG & 16.4 & $\begin{array}{l}\text { Validation } \\
\text { stop }\end{array}$ \\
\hline 730 & 2 & TANSIG & 16.2 & $\begin{array}{l}\text { validation } \\
\text { stop }\end{array}$ \\
\hline 1460 & 2 & TANSIG & 15.9 & $\begin{array}{l}\text { Validation } \\
\text { stop }\end{array}$ \\
\hline 365 & 2 & PURELIN & 18.9 & Min gradient \\
\hline 730 & 2 & PURELIN & 18.3 & Min gradient \\
\hline 1460 & 2 & PURELIN & 18 & $\begin{array}{c}\text { Max MU } \\
\text { reached }\end{array}$ \\
\hline 365 & 5 & TANSIG & 16 & $\begin{array}{l}\text { Validation } \\
\text { stop }\end{array}$ \\
\hline 730 & 5 & TANSIG & 8.48 & $\begin{array}{l}\text { Validation } \\
\text { stop }\end{array}$ \\
\hline 1460 & 5 & TANSIG & 5.3 & $\begin{array}{l}\text { Validation } \\
\text { stop }\end{array}$ \\
\hline 365 & 5 & PURELIN & 17.7 & $\begin{array}{l}\text { Max MU } \\
\text { reached }\end{array}$ \\
\hline 730 & 5 & PURELIN & 17.6 & $\begin{array}{l}\text { Max MU } \\
\text { reached }\end{array}$ \\
\hline 1460 & 5 & PURELIN & 17.5 & $\begin{array}{l}\text { Max MU } \\
\text { reached }\end{array}$ \\
\hline 365 & 8 & TANSIG & 13.1 & $\begin{array}{l}\text { Validation } \\
\text { stop }\end{array}$ \\
\hline 730 & 8 & TANSIG & 5.73 & $\begin{array}{l}\text { Validation } \\
\text { stop }\end{array}$ \\
\hline 1460 & 8 & TANSIG & 1.52 & $\begin{array}{l}\text { Validation } \\
\text { stop }\end{array}$ \\
\hline 365 & 8 & PURELIN & 16.9 & Min gradient \\
\hline 730 & 8 & PURELIN & 16.6 & Min gradient \\
\hline 1460 & 8 & PURELIN & 16.1 & Min gradient \\
\hline
\end{tabular}

Table 3. Performance Comparison for Ten Layer based ANN with Weather data for last 10 years [17]

\begin{tabular}{|c|c|c|c|c|}
\hline Samples & $\begin{array}{c}\text { Neuron } \\
\text { layer }\end{array}$ & $\begin{array}{c}\text { Transfer } \\
\text { function of } \\
\text { HL }\end{array}$ & MSE & $\begin{array}{c}\text { Stopping } \\
\text { criteria }\end{array}$ \\
\hline 365 & 4 & TANSIG & 16.1 & $\begin{array}{c}\text { Validation } \\
\text { stop }\end{array}$ \\
\hline 730 & 4 & TANSIG & 12.5 & $\begin{array}{c}\text { validation } \\
\text { stop }\end{array}$ \\
\hline 1460 & 4 & TANSIG & 7.23 & $\begin{array}{c}\text { Validation } \\
\text { stop }\end{array}$ \\
\hline 365 & 4 & PURELIN & 18.8 & Min gradient \\
\hline 730 & 4 & PURELIN & 18.6 & Min gradient \\
\hline
\end{tabular}

\begin{tabular}{|c|c|c|c|c|}
\hline 1460 & 4 & PURELIN & 18.2 & $\begin{array}{c}\text { Max MU } \\
\text { reached }\end{array}$ \\
\hline 365 & 10 & TANSIG & 13.4 & $\begin{array}{c}\text { Validation } \\
\text { stop }\end{array}$ \\
\hline 730 & 10 & TANSIG & 4.02 & $\begin{array}{c}\text { Validation } \\
\text { stop }\end{array}$ \\
\hline 1460 & 10 & TANSIG & 1.44 & $\begin{array}{c}\text { Validation } \\
\text { stop }\end{array}$ \\
\hline 365 & 10 & PURELIN & 17.9 & $\begin{array}{c}\text { Max MU } \\
\text { reached }\end{array}$ \\
\hline 730 & 10 & PURELIN & 17.8 & $\begin{array}{c}\text { Max MU } \\
\text { reached }\end{array}$ \\
\hline 1460 & 10 & PURELIN & 17.6 & $\begin{array}{c}\text { Max MU } \\
\text { reached }\end{array}$ \\
\hline 365 & 16 & TANSIG & 10.4 & $\begin{array}{c}\text { Validation } \\
\text { stop }\end{array}$ \\
\hline 730 & 16 & TANSIG & 2.75 & $\begin{array}{c}\text { Validation } \\
\text { stop }\end{array}$ \\
\hline 1460 & 16 & TANSIG & 0.201 & $\begin{array}{c}\text { Validation } \\
\text { stop }\end{array}$ \\
\hline 365 & 16 & PURELIN & 16.8 & \begin{tabular}{c} 
Min gradient \\
\hline 730
\end{tabular} \\
\hline 1460 & 16 & PURELIN & 16.4 & Min gradient \\
\hline
\end{tabular}

The paper also distinctly proposes an ANN based Anomalous Weather Detection Technique without the use of dedicated hardware or equipment.

\section{CONCLUSION \& FUTURE WORK}

On the basis of discussed experimental results, it is concluded that the proposed system is able to resolve some of the issues discussed earlier. The performance of the proposed system is equivalent, if not better than other systems currently being used. The performance of the system is defined in terms of data modelling, handling missing data, execution time and mean square error for test data. The proposed methodology currently functions only on Temperature data; although the same method can be used to predict weather prediction parameters like: Relative Humidity, Barometric Pressure, Wind Speed \& Direction, etc. A further extension to the system could be that, all major weather prediction parameters be used simultaneously to achieve more effective and advanced weather patterns. Also the proposed methodology effectively determines weather anomalies in daily temperatures and mathematically proves the effects of pollution and Global Warming on various cities.

\section{REFERENCES}

[1]. Imran Maqsood, Muhammad Riaz Khan, Ajith Abraham, "Weather Forecasting Models Using Ensembles of Neural Networks", Intelligent Systems Design and Applications - Volume 23 - Advances in Soft Computing, Page 33-42, Springer - Verlag Berlin Heidelberg 2003.DOI - 10.1007/978-3-540-449997_4.

[2]. Ratna Nayak , P. S. Patheja, Akhilesh Waoo, "An Enhanced Approach for Weather Forecasting Using Neural Network", Proceedings of the International Conference on Soft Computing for Problem Solving, Page 833-839, December 20-22, 2011. DOI 10.1007/978-81-322-0491-6_76. 
[3]. World of Earth Science - 2003, "Weather Forecasting Copyright", The Gale Group, Inc.

[4]. Steve Graham, Claire Parkinson, Mous Chahine, "Weather Forecsrting through the Ages", 2002.

[5]. Iza Sazanita Isa, "Weather Forecasting Using Photovoltaic System and Neural Network", Computational Intelligence, Communication Systems and Networks - 2010, Second International Conference IEEE, DOI - 10.1109/CICSyN.2010.63.

[6]. Yuan Quan, "Research on weather forecast based on neural networks. Intelligent Control and Automation", Page: 069 - 1072, Vol.2, 2000, ISBN: 0-7803-5995$\mathrm{X}$.

[7]. Sharma, A., "A Weather Forecasting System using concept of Soft Computing: A new approach", Advanced Computing and Communications, ADCOM IEEE 2006, Page: 353 - 356, DOI 10.1109/ADCOM.2006.4289915.

[8]. Bondalapati, K.D, "Neural network model to predict deoxynivalenol (DON) in barley using historic and forecasted weather conditions", Agro-Geoinformatics (Agro-Geoinformatics), IEEE 2012, DOI 10.1109/Agro-Geoinformatics.2012.6311618.

[9]. Ahmadi, A, "Hybrid model for weather forecasting using ensemble of neural networks and mutual information", Geoscience and Remote Sensing Symposium (IGARSS) 2014 IEEE, DOI 10.1109/IGARSS.2014.6947305.

[10].Sannakki, S., "A neural network approach for disease forecasting in grapes using weather parameters", Computing, Communications and Networking Technologies (ICCCNT) 2013 - Fourth International Conference IEEE, DOI 10.1109/ICCCNT.2013.6726613.

[11].Chow, T.W.S., "Neural network based short-term load forecasting using weather compensation", Power Systems, IEEE 1996 (Volume: 11, Issue: 4) Page: 1736 - 1742, DOI -10.1109/59.544636
[12].Chen, S.-T., "Weather sensitive short-term load forecasting using no fully connected artificial neural network. Power Systems", IEEE Transactions 1992 (Volume: 7, Issue: 3), Page: 1098 - 1105, DOI 10.1109/59.207323_1105.

[13].ShuFang Wu, Jie Zhu, Yan Wang., "Weather Forecasting Using Naïve Bayesian", Advances in Intelligent and Soft Computing - Springer Berlin Heidelberg 2012, Volume 1, Page: 337 - 341, DOI 10.1007/978-3-642-29387-0_50.

[14].Antoni Buszta, Jacek Mazurkiewicz, "Climate Changes Prediction System Based on Weather Big Data Visualisation", Proceedings of the Tenth International Conference on Dependability and Complex Systems DepCoS-RELCOMEX, Springer International Publishing 2015, Page: 75 - 86, DOI 10.1007/978-3-319-19216-1_8.

[15].Chunlin Xu,Tao Li, Xuemei Huang, Yaping Jiang, "A Weather Forecast System Based on Artificial Immune System", First International Conference, ICNC 2005, Springer Berlin Heidelberg Proceedings, Part II, Page: 800 - 803, DOI - 10.1007/11539117_112.

[16].Ziniu Xiao, Bo Liu, Hua Liu, De Zhang, "Progress in climate prediction and weather forecast operations in China", Advances in Atmospheric Sciences, SP Science Press Volume 29, Issue 5 , Page: 943 - 957, 2012, DOI - 10.1007/s00376-012-1194-9.

[17].Kumar Abhishek, M.P. Singh, Saswata Ghosh, Abhishek Anand, "Weather Forecasting Model using Artificial Neural Network", Procedia Technology, 2nd International Conference on Computer, Communication, Control and Information Technology, Volume 4, 2012, Page: 311-318, DOI 10.1016/j.protcy.2012.05.047

[18].CEES Weather Station - Weather Parameters, http://cees.tamiu.edu/cees/weather/parameters.html 